\title{
Reflexive Epistemology in Jaws and Jurassic Park
}

Robert Geal

Jaws is useful to scholarship not only because of its interesting narrative, aesthetic style, performances, and production history, but because it is amenable to academic interpretations from a number of different, potentially contradictory theoretical paradigms. These divergent analyses, in addition to offering their own accounts of how Jaws functions, also suggest that certain films relate to contested theoretical premises in inconsistent, ambiguous and overlapping ways. If rival academic paradigms are really so irreconcilable, as they so frequently claim, then a film which can be convincingly analysed by more than one rival approach suggests either some fundamental flaw in one of the paradigms, or that significant elements of the film respond to the competing paradigms' very different conceptualisations of how film operates. Proponents of competing theories typically take the former approach, making the case that certain methodological errors invalidate the rival account. This chapter, however, is an exploration of the latter possibility. I argue that the filmmaking and spectatorial motivations over which competing theories claim an explanatory monopoly can be manipulated in intersecting and symbiotic ways in films like Jaws and another Spielberg film that stages horrific non-human violence against a backdrop of human duplicity, Jurassic Park (1993).

The chapter outlines how existing scholarship conceptualises filmmaking and spectatorship, discussing rival claims about how Spielberg attempts to engender certain different spectatorial responses to Jaws. I then analyse the ways that the film manipulates ostensibly contradictory dramas associated with these rival scholarly theories, suggesting that Spielberg intuits diverse forms of spectatorial pleasure, and is able to create film which elicits multiple spectatorial responses. I finish by briefly comparing Jaws to Jurassic Park, 
in order to establish how Spielberg's multiple dramas relate to potential technological determinants.

\section{Competing theoretical approaches to Jaws}

For the sake of brevity, and because certain scholarly theories have focused more attention on Jaws than others, I will focus on two leading paradigms, poststructuralism and cognitivism, both of which claim to reveal why filmmakers construct films in certain ways, and the kind of activities spectators engage in while watching films. Both poststructuralism and cognitivism conceptualise theoretical enterprise and filmmaking as distinct activities. ${ }^{1}$ The scholar does not think of the filmmaker as working in explicitly theoretical terms.

I shall argue that theorising and filmmaking are not as distinct as is normally assumed. Any film theory claims, with caveats about various historical, socio-cultural and/or industrial conditions, that filmmakers attempt to engender a certain range of audience responses. Rival paradigms disagree about the nature of those filmmaking motivations and spectatorial responses (which may be thought of as either conscious or unconscious), but each theory offers a different explanation for the activities of everyone involved in making or watching a film. My suggestion here is that the non-scholarly filmmaking and spectatorial activities relevant to any particular film need not necessarily be only those advocated by a single academic paradigm, with alternate theoretical interpretations a diametrically opposed refutation of those other interpretations. So, it need not necessarily be the case that a film is either evidence of the filmmakers' and spectators' unconscious desires, or conversely evidence of the filmmakers' and spectators' rational cognition. Instead, filmmaking in films like Jaws and Jurassic Park can attempt to activate diverse audience responses that film theories have hitherto claimed are mutually exclusive.

The two principal paradigms that have been applied to Jaws are, first, a hybrid of semiotics, (neo-)Marxism and psychoanalysis, which, for the sake of simplicity can be 
termed poststructuralism, ${ }^{2}$ and, second, a form of Post-Theory that is most frequently called cognitivism. ${ }^{3}$ The ostensible irreconcilability of these approaches is demonstrated by the extent to which proponents of these theories characterise them as epistemologies - that is as complete philosophical models for understanding what can be known about human consciousness and what light that can shed on film. ${ }^{4}$ It is this epistemological dimension that makes poststructuralism and cognitivism irreconcilable, because they make diametrically opposed claims about how consciousness works, and about how this consciousness then makes and interprets films.

For poststructuralism, consciousness is determined by factors outside its direct control. Socio-cultural and economic conditions create what the French psychoanalyst, Jacques Lacan, calls the 'Symbolic Order' which human subjects assent to enter, and which constructs their consciousness (at least in part). ${ }^{5}$ One of the defining features of the Symbolic Order is René Descartes' characterisation of humanity as the res cogitans ('thinking thing') at the centre of meaning and being. ${ }^{6}$ Cartesian subjectivity generates aesthetics which replicate the centrality of the res cogitans, so that art imitates a certain illusion about life. Renaissance perspective painting was the pioneering form of this aesthetic, constructing an impression of reality which seems to flow out from the perfectly positioned and centralised observer. Film, too, constructs imagery which fixes the spectating subject as the locus of action and meaning. Film, however, consists of moving images and so the perspectival stability of the spectating res cogitans subject is constantly in flux. Like the famous oblique skull in Hans Holbein's painting The Ambassadors (1533), film's perspectival vision is incomplete, and therefore potentially threatening to the stability of the Cartesian subject. For cognitivism, on the other hand, the human mind is rational rather than irrational. Humans consciously determine their ways of thinking and behaving (and seeing), rather than being unconsciously determined by an internalised Symbolic Order. ${ }^{7}$ 
Jaws has been understood as an exemplar of both of these key epistemological claims. Stephen Heath's poststructuralist analysis, for example, stresses how realist films like Jaws inevitably attempt to compensate for the incomplete nature of both perspectival vision and the Symbolic Order that structures the Cartesian illusion of geometric perspective. ${ }^{8}$ Realist films compensate for this incompletion through a visual regime that repeatedly re-centres the inevitably decentred spectator. The cathartic nature of this re-centering is so powerful that film repeats the psychological mechanism at the level of narrative. As Heath puts it, cinema is fundamentally

the organization of a point of view through the image-flow, the laying out of an intelligibility, the conversion of seen into scene as the direction of the viewing subject. [...] [B]ut film, in its flux, can also produce discontinuities, disruptions, 'shocks'. Hence, from the start, there is a need to reconstruct the truth of vision, to establish ways of holding a film's relations as the coherence of the subject-eye - continuity techniques, matches, 30-degree and 180-degree rules, codes of framing, and so on. Indeed, the drama of vision becomes a constant reflexive fascination in films. [...] Jaws is $[\ldots]$ relevant with its play on the unseen and the unforeseeable, the hidden shark and the moments of violent irruption. [...] Film is the constant process of a phasing-in of vision, the pleasure of that process - movement and fixity and movement again, from fragment (actually thematised in Jaws as dismemberment) to totality (the jubilation of the final image). ${ }^{9}$

What Heath calls the 'drama of vision', then, is an oscillation between a perspectival stability structured around conventionalised film grammar, and reflexive metaphorical filmmaking commentaries about the limitations of this perspectival stability. ${ }^{10}$ Jaws has a 
drama of vision which reflexively renders film's inevitable perspectival instability into the shark's ambiguously shown movements, brief violent shocks, and fragments of bodies representing the fragmentary nature of cinematic framing, editing and of the Symbolic Order.

In contrast, from a cognitive perspective, Noël Carroll approaches Jaws in relation to what he calls 'erotetic narration'. ${ }^{11}$ This is an almost ubiquitous narrative structure, present in many films, in which

scenes, situations, and events that appear earlier in the order of exposition in a story are related to later scenes, situations, and events in the story, as questions are related to answers. [...] Such narration, which is at the core of popular narration, proceeds by generating a series of questions that the plot then goes on to answer. ${ }^{12}$

Carroll states that erotetic narration in Jaws and many other films

is driven explicitly by curiosity. It engages its audience by being involved in processes of disclosure, discovery, proof, explanation, hypothesis, and confirmation. Doubt, skepticism, $[\ldots]$ are predictable foils to the revelation (to the audience or to the characters or both) of the existence of the monster. ${ }^{13}$

Carroll therefore explains filmmaking motivations and spectatorial engagement very differently from Heath. For Heath, the spectator gains unconscious pleasure from threats to perspectival security which are quickly and repeatedly resolved. Filmmaking in Jaws unconsciously manipulates this spectatorial pleasure by generating and resolving ambiguity about the shark's movements, by including brief shocks, and by reflexively turning 
fragments of imagery into fragments of limbs: both filmmakers and spectators are motivated by unconscious forces outside their full control. For Carroll, the spectator gains pleasure by consciously decoding information, speculating about how characters might respond to that information, and having these speculations confirmed or refuted. Jaws - or rather the filmmakers - consciously manipulates spectatorial pleasure by providing ambiguous information, encouraging speculation about how characters might respond to this information, and by confirming or refuting these speculations. Filmmakers, as the leading cognitivist, David Bordwell, puts it, 'solicit story-constructing and story-comprehending activities from spectators'. ${ }^{14}$ Although Carroll does not use the following precise terminology, it makes sense to define the filmmaking motivations and spectatorial pleasures associated with erotetic narration as the 'drama of knowledge', ${ }^{15}$ in contradistinction to Heath's 'drama of vision' since both of these theoretical accounts claim that filmmakers attempt to elicit certain dramatic responses from audiences. ${ }^{16}$

\section{Jaws' multiple dramas}

Jaws's opening scene demonstrates how filmmaking motivations seem to encourage audiences to respond to both of these dramas. In terms of the drama of vision, the opening sequence establishes the film's distinction between ambiguous imagery that threatens to decentre the spectator - the 'violent underwater movement tied to no human point of view' ${ }^{17}$ and the catharsis of the cut to the perspectival and grammatical coherence of the beach party - 'the cut is heavily marked by changes in colour, $[\ldots]$ in music, $[\ldots]$ and in rhythm' ${ }^{18}$ The oscillation between these juxtaposed image systems can then play out over the course of the film. These 'knot together as figures over the film. [...] [T]he underwater shot is then used [...] to signify the imminence of attack'. ${ }^{19}$

In terms of the drama of knowledge this scene sets up the first element of what Carroll identifies as a 
plot structure [which] has four essential movements or functions. They are: onset, discovery, confirmation, and confrontation. The first function [...] is onset. Here the monster's presence is established for the audience. For example, in the film Jaws, we see the shark attack. We know the monster is abroad. ${ }^{20}$

Carroll is principally concerned with the presentation of a diegetic threat to characters rather than with how that diegetic threat might alternately/also function as a threat to spectatorial subjectivity. The shark's underwater point of view shot establishes a particular form of visual representation which can then be repeated to prompt spectators to speculate about another imminent attack. In erotetic terms, it is entirely appropriate for this visual sign of an impending attack to consist of an underwater shot which has a different colour palette, musical accompaniment, and form of camera movement. These alterations to the rest of the film's more geometrically and grammatically ordered compositions are elements of conscious filmmaking attempts to set up spectatorial expectations which can then signal the subsequent repeated monstrous 'onsets' to audiences consciously decoding such cues.

Both of these competing epistemological perspectives thereby explain the same filmic elements - tonal differences related to colour, music and camera movement - in very different terms, with each assigning filmmakers and spectators very different motivations. However, a film scholar can only decide which explanation (s)he finds convincing enough to invalidate the other explanation based on a priori decisions about how human consciousness relates to film generally. The film text itself can bear the burden of both of these epistemological claims, and the filmmaking may therefore attempt to elicit both the drama of vision and the drama of knowledge. 
The two different paradigms certainly stress, however, the importance of two different elements of the filmmaking. Carroll states that, in addition to establishing a visual regime that will mark the reappearance of the shark's threat, the monstrous presence invites audience speculation about how such a threat will be countered. Thus, what Heath interprets as a threat to the security of spectatorial vision, Carroll interprets as cues about how the narrative will develop:

The onset of the creature, attended by mayhem or other disturbing effects, raises the question of whether the human characters in the story will be able to uncover the source, the identity and nature of these untoward and perplexing happenings. This question is answered in the second movement or function in the kind of plot we are discussing; I call it discovery. ${ }^{21}$

The drama of vision's oscillating grammatical inconsistency/consistency is therefore also the drama of knowledge's movement from unknowing to knowing.

This element of the relationship between the two dramas actually begins to point towards some kind of divergence, with one theory offering a more convincing account of certain scenes than the other theory and vice versa. Heath's focus on the oscillations from grammatical/geometric stability to a disruptive instability, and Carroll's plot function 'discovery', both have the potential to explain how audiences might experience suspense in terms of how these dramas play out as the film develops, but these are quite different kinds of suspense. The drama of knowledge exploits suspense about which characters have access to what information - for Carroll, '[s]uspense in fictional narratives is generated as an emotional concomitant of a narrative question that has been raised by earlier scenes and events in a story'.22 The drama of vision exploits suspense about how film might suddenly 
shift from stability to instability at any moment - the 'play on the unseen and the unforeseeable, the hidden shark and the moments of violent irruption'. ${ }^{23}$

In the opening scene, and subsequent repetitions of the underwater point of view signalling an attack, these two forms of suspense closely overlap. The spectator can simultaneously experience both the drama of knowledge (asking whether another attack is imminent, who will be the victim, and whether the attack will be successful or averted) and the drama of vision (unconsciously experiencing a momentary de-centering that will quickly be cathartically resolved). Indeed, both of these dramas can also be experienced when the film manipulates and subverts the connection between the underwater attack and the shark. Heath writes that '[o]nce systematized, [this connection] can be used to cheat: it occurs to confirm the second daytime beach attack, but this is only two boys with an imitation fin ${ }^{24}$ so that the drama of vision can threaten spectatorial security without directly threatening the diegetic characters. This cheat can fit into an erotetic context by subverting established expectations, manipulating the spectator's involvement in 'processes of disclosure, discovery, proof, explanation, hypothesis, and confirmation' ${ }^{25}$ However, other scenes in Jaws seem more conducive to one dramatic form of suspense than the other.

For example, the scene that introduces Brody (Roy Scheider) and his family engenders the suspense associated with the drama of knowledge but not the suspense associated with the drama of vision. The scene does not immediately establish that Brody is Chief of Police, but an erotetic suggestion is made that he might be some kind of authority figure, since he answers a phone and takes part in a conversation about the events shown in the first scene, though their deadly nature is not hinted at in the half of the phone conversation that the spectator can hear. Just before Brody answers the phone his young son Michael (Chris Rebello) enters the house showing a bleeding hand cut in a minor accident. As Brody picks up the phone, Michael asks his mother, Ellen (Lorraine Gary), if he can go 
swimming. She replies that he can after she has washed his hand. A clear locational connection to the opening scene has already been established via a match between a nighttime long shot of the sea from the shore and a day-time shot of the sea from the shore into which Brody emerges from offscreen. The spectator therefore knows that a fatal shark attack has recently taken place near to the Brody house. Suspense is created because the spectator is aware that swimming with a bleeding wound in such waters might be dangerous.

Suspense here operates within the context of what Carroll calls

phasing in the development of [the] onset movement. That is, the audience may put together what is going on in advance of the characters in the story; the identification of the monsters by the characters is phased in after the prior realizations of the audience. That the audience possesses this knowledge, of course, quickens its anticipation. ${ }^{26}$

The erotetic nature of this suspense is heightened by Brody's phone conversation and the dramatic irony of Michael preparing to swim with a bleeding wound.

However, the erotetic suspense generated here does not overlap with the kind of suspense associated with the drama of vision. While Brody is on the phone the spectator is unlikely to suspect that a shark is going to burst through the windows. The probability of Heath's 'violent irruption" ${ }^{, 27}$ at this precise moment is practicably zero. (Only in the Sharknado franchise (2013-18) are such 'violent irruptions' possible in this type of inappropriate location.) This scene therefore exploits the drama of knowledge but not the drama of vision. Nevertheless, the drama of knowledge does point temporally forwards to subsequent dramas of vision. Even if the spectator does not expect a shark attack on Michael at that moment, he or she may speculate that one will occur later in the film. The scene's erotetic drama of knowledge points towards a later potential drama of vision, so that even 
when the film does not directly combine these dramas together, it does construct a temporal landscape in which they can interact.

In other scenes, the kind of suspense generated by the drama of vision takes precedence. The famous scare of Gardner's (Craig Kingsbury) bloated head (or possibly whole corpse) bobbing into the hole in his boat's hull is a clear example of Heath's 'play on the unseen and the unforeseeable, the hidden [corpse] and the moments of violent irruption'. ${ }^{28}$ Warren Buckland states that Spielberg achieves a

strong audience reaction [because] the head appears almost 'too soon'; that is, it appears unexpectedly, rather than after a long period of suspense. Spielberg could have delayed the appearance of the head, but this would have created the expectation that something was going to happen. ${ }^{29}$

Hooper (Richard Dreyfuss) only enters the frame to investigate the hole a moment before the head emerges. The 'violent irruption' is therefore part of the logic of a form of suspense in which a shock may suddenly create temporary spectatorial instability at any moment, rather than a form of suspense which invites specific speculations about specific threats.

The traumatic nature of this threat to perspectival stability is demonstrated by the image that Spielberg associates with the visual drama - a lifeless head, somewhat like Holbein's skull, representing the annihilation of subjectivity inherent in the temporary collapse of the Symbolic Order's unity. Gardner's dead head, moreover, allegorises the drama of vision's threat to the spectator's otherwise unthreatened security of seeing, with one of the dead eyes eaten away to reveal the tendrils of the brain's optic nerve, the other fully open but incapable of sight 
Insert fig 1: Gardner's unseeing eyes as reflexive allegory for the limitations of seeing.

The close-up of the head, moreover, follows a close-up of Hooper staring directly at the camera so that the spectator is offered Hooper's traumatised point of view after seeing him from what turns out to be the dead eye's impossible point of view.

Insert fig. 2: Hooper's traumatised reaction, from the dead unseeing Gardner's point of view.

Here, the mechanisms of shot/reverse shot, which conventionally play such an important role in re-centering the decentred spectator, become a traumatic interrogation of filmic Cartesian subjectivity. This form of filmmaking does not just diegetically threaten a character, but also cinematically threatens the spectator's subjectivity, briefly demonstrating that vision and subjectivity, so centrally linked in Descartes' res cogitans, are not necessarily the same thing.

The 'violent irruption' of Gardner's head also relates to Heath's claim about how film's constant movement from 'fragment [...] to totality' is 'thematised in Jaws as dismemberment ${ }^{30}$ Close inspection of the scene suggests that the head is still attached to (at least part of) the body. Gardner's head is shown in two shots. In the first it bobs into the hole in the hull on the left side of the frame, with Hooper peering into the hole from the right. The intact part of the hull conceals almost all of the body below the neck, and it is the head which appears first. In the second shot, Hooper's torch picks out the head from the surrounding darkness (see Fig.1). Thus, if the head is not diegetically fragmented, then it is cinematically fragmented - Buckland refers to a head rather than a corpse, confirming that 
the scene suggests fragmentation even if it does not show it directly. ${ }^{31}$ Hooper, too, collects a fragment of the shark, in the form of a large tooth imbedded in the hull.

This particular moment of suspense is associated with the drama of vision's 'play on [...] the hidden shark and the moments of violent irruption' ${ }^{32}$ Because the head appears 'too soon' it prevents a direct erotetic question-and-answer drama - the answer appears before the audience has had time to ask the question. It is also the case, though, that this scene overall creates a form of suspense more consistent with the drama of knowledge. Hooper and Brody, after all, have just discovered that the other shark has not eaten the 'Kintner boy' (Jeffrey Voorhees). They set out on their night-time boat trip to find answers to questions, and these multiply as the scene goes on: Is there a shark or any evidence of its behaviour out here? What does Hooper's underwater tracking technology uncover? What is that object floating in the darkness? What caused the damage to the boat? What will Hooper find underwater? What is the object he pulls out of the hull?

Some of these questions are answered quickly - the object is Gardner's boat, Hooper's torch reveals a shark's tooth - but some are answered ambiguously and some of the answers are deferred. The technology finds 'probably [but not definitively] just a school of mackerel', and Hooper's boat's searchlight pans across a silhouette of Gardner's boat's hull to show a large hole above water that might have been caused by a shark attack or by an accidental boat collision. This erotetic structure invites the drama of knowledge's suspense about the exact nature of the threat. The spectator is invited to speculate that Gardner's boat might have been attacked by the shark and that the shark could still be nearby and attack again. The reintroduction, when Hooper goes overboard, of both underwater camerawork and John Williams's menacing music reinforces this suspense.

There are, in fact, two holes in the hull below water. Hooper picks the tooth out of the first, and Gardner's head bobs into the second. The suspenseful threat of the shark 
spreads across the entire scene, but the tooth explicitly links the threat to the holes in the hull. Erotetic suspense invites speculation that the water around the boat generally, and the holes in the hull specifically, contain a diegetic threat to Hooper associated with the shark. Thus, when the head bobs into the second hole, although it comes 'too fast' to elicit a direct question about what threat will emerge from the hole, the broader contours of that question have been generated erotetically. The precise effect eliciting the drama of vision has been facilitated and enhanced by the scene's symbiotic drama of knowledge. The drama of vision can occur whenever a film 'play[s] on the unseen and the unforeseeable, the hidden [...] and the moments of violent irruption' ${ }^{33}$ However, the power of these elements in this scene is derived from a setup inherent in a form of suspense that provokes spectators to erotetically speculate about the unseen and the unforeseeable. The moment of 'violent irruption' can therefore be somewhat prepared for, but also a shock.

I mentioned above that the shock element of the suspense associated with the drama of vision can occur at any time, in the sense that this suspense does not require a specific erotetic setup. If the camera lingered longer over the hole in the hull, then an erotetic form of suspense would generate a definitive question - what is in the hole? The drama of vision's suspense is built on a temporally longer scale because a shocking 'violent irruption' might occur at any moment. But such 'violent irruptions' require not only appropriate settings but also an appropriate erotetic backdrop. The shock of the head's irruption might be an answer to a direct question that hasn't been posed, but the shock occurs as part of a broader erotetic landscape, in which the more general suspenseful questions about what happened to Gardner and his boat have been posed. The drama of vision's 'violent irruptions' cannot, then, occur at any moment, but only at moments sanctioned and foreshadowed by the drama of knowledge. 
The filmmaking here, then, seems to intuit reflexively both of these potential forms of spectatorial pleasure. This reflexivity consists of not only an intuition about how audiences respond to dramas, but also a close link between the narrative and cinematic elements of these dramas. I mentioned above how Gardner's head links together the drama of vision's cinematic fragments (compositional framing, lighting to pick out the head, shot/reverse shot between the points of view of a traumatised character's head and a dead head) with narrative fragments (body parts, tooth, eaten eye and unseeing eye). The drama of knowledge also has certain reflexive links between narrative and cinematic style. Hooper's searchlight panning over Gardner's boat is simultaneously a narrative element of the drama of knowledge - providing characters and spectators with information - and a reflexive element of the drama of knowledge. The beam of searchlight both resembles the light from a film projector, and also reveals and partly conceals information in the same way as the film projection does at this moment. Spielberg seems to not only intuit the dramatic potential of filmmaking and spectatorial motivations associated with two different academic epistemologies, but he also seems to recognise the potential of inscribing these motivations into intrinsically cinematic metaphors. ${ }^{34}$

The film's other principal 'violent irruption' occurs in the last act, when the shark lurches out of the water behind Brody as he throws chum overboard. In this instance the erotetic element is downplayed. Yes, Brody, Hooper and Quint (Robert Shaw) are out searching for the shark, prompting questions about how and when they will find it. It is also the case that the chum Brody is shovelling in the water is narratively associated with the shark because it is a means to attract it as well as being visually associated with the shark: When the Orca leaves harbour the film dissolves to a blood-red sea. This has been seen before, during the shark's second and third attacks, but on this occasion the camera moves up to show that the blood comes from the chum. These associations function as part of what 
Carroll calls the drama of knowledge's 'processes of disclosure, discovery, proof, explanation, hypothesis, and confirmation', making narrative and visual connections between the chum and the shark. ${ }^{35}$

Nevertheless, the suddenness with which the shark rears up, even more than when Gardner's head appears, prevents a direct question about the shark's appearance from arising. The first erotetic signs of the shark's appearance have already been suspended these were small movements that Quint notices on his fishing line, which neatly synthesise a drama of vision about the unseen with a drama of knowledge about what information these small movements might reveal. The spectator's expectations about this first bundling of dramas have been subverted, as the shark escaped unseen. A dissolve then signals that time has passed. Hooper is playing solitaire with cards, while Brody is complaining about Quint telling him to resume chumming. Brody continues to complain while his face is turned away from the water, so that he does not immediately see the shark's 'violent irruption'. These elements combine to downplay the erotetic element. Although there is an overall question concerning the shark's whereabouts, it makes its appearance precisely when the urgency of the question is temporarily suspended. (This is different from the moment when the shark interrupts the crew's drunken singing, because on that occasion the unseen presence of the shark is signalled to the spectator first, via a shot of the attached barrel rising to the surface of the sea).

The extent to which the erotetic element of the shark rearing up behind Brody is downplayed is demonstrated by the famous adlibbed statement that he utters in response 'You're gonna need a bigger boat'. A few moments later this statement will be repeated as a question, 'You're gonna need a bigger boat, right?', once the erotetic drama of knowledge returns to precedence. 'How do we handle this?' Brody asks, twice, as the crew scrambles into action, a close-up of slipping feet on the side of the boat inviting the spectator to ask 
whether one of them will plummet overboard. But prior to this resumption of erotetic drama, Brody's statement is definitive rather than interrogative, just as the shark lurch is a movement from unseeability to a 'violent irruption' rather than a clearly cued outcome of an erotetic setup - the emergence of the shark is not an answer to the direct question 'what is behind Brody?', even if the broader question about the shark's whereabouts motivates the scene overall. Here again Spielberg temporarily separates the dramas of vision and of knowledge, the better to exploit their potential effects on audiences.

\section{The question about technological determinism - how the dramas of vision and knowledge in Jurassic Park compare to Jaws}

I want to finish up by making a quick comparison with how Spielberg exploits these dramas in Jurassic Park. Keeping the shark offscreen in Jaws has often been explained as a solution to technical difficulties with the pneumatic prop shark nicknamed 'Bruce'. The coincidentally-named Bruce Isaacs states that the

shark remains [predominantly] unseen, incrementally swelling in the mind of the spectator. $[\ldots]$ The shark had been storyboarded into all of the attack sequences, and would have been used extensively in production had it not broken down prior to shooting; the absent image is, ironically, a function of technological failure. ${ }^{36}$

There may some merit to this claim, and to Isaacs' analysis of how, by the time of Jurassic Park, 'Spielberg [...] had recognized the primal desire of the spectator to encounter images of excess, technologies of exhibition, and mass cinema's orientation toward spectacle'. ${ }^{37}$

Jurassic Park certainly delivers this form of excessive spectacle in a way that Bruce's technological limitations made impossible. Geoff King claims that even though the dinosaurs are sometimes offered as a 'contemplative spectacle' ${ }^{38}$ to be gazed at in 
technological awe, their spectacular nature always has specific narrative purposes. Thus, the first lingering spectacle of a dinosaur is presented

as an object for our contemplation, but it is not bracketed off from the narrative space for the precise reason that our contemplative gaze is motivated by that of the protagonists, getting their first stunned sight of the recreated dinosaurs' ${ }^{39}$

This combination of narrative and spectacle can activate both the drama of vision and the drama of knowledge. In terms of the former, the first dinosaur, an enormous herbivore, poses no threat, to either the characters or the spectator's security, as it ambles sideways rather than lurches forwards. Indeed, at this point the drama focuses on the pleasures of looking. The spectator is shown the dinosaur only after seeing palaeontologist Grant (Sam Neill) looking with wonder. His vision is a form of pleasure beyond words - he reaches out to turn the head of Ellie (Laura Dern) so that she can share his gaze. The camera repeats an upwards movement as both characters stand incredulously. At the same time, in terms of the drama of knowledge, the spectator is invited to speculate about how these miraculous events came about, and what their consequences might be.

The full extent of these dramas, however, can only be experienced when the spectacle of the dinosaurs become threatening (both diegetically and spectatorially). These threats, moreover, frequently downplay excessive spectacle in a manner that is reminiscent of Jaws's barely seen monster. Jurassic Park begins, for example, with a shot reminiscent of the scene with Gardner's boat. In a darkness backlit with shafts of white light, something menacing approaches. This approach, however, is shown through movements in trees which eventually reveal a forklift carrying a crate, rather than through the CGI spectacle of a dinosaur. The attack of the velociraptor in the crate is also mostly unseen, with only the 
effects on the human worker shown. (The unseen attacks of the velociraptors are repeated a little later when a cow is lowered into their enclosure.) The only part of the velociraptor seen in this scene is its menacing eye, intercut with the desperate Muldoon's (Bob Peck) eye. Here, vision is neither safe nor stable. The scene also has a clear erotetic component: What is emerging from the trees? What is in the crate? Will the events transpiring end in a tragedy, as is suggested by the ominous lighting and music? Will the worker be rescued or killed?

The eye of the T-Rex, too, is part of what makes the drama of vision's mostly unseen monstrosity just as menacing as the full CGI spectacle. The T-Rex is introduced by absence: cars pull up at its enclosure to see only a sign of its non-presence in the form of a tied-up goat. After the power outage, the approach of the T-Rex is seen indirectly. Indeed, the first sign of its approach is a sound rather than a sight, with its footsteps causing ominous audible rumbles. These rumbles then translate into vicariously monstrous visual images - the water in a cup vibrating (later repeated as vibrating water in a giant footprint), a point of view shot through night-vision goggles of the post and tether without the goat, the goat's severed limb falling onto the car's glass roof (dismemberment, again). The first actual glimpse of the TRex is little more spectacular than Bruce's fin, merely a claw scraping at the powerless electric fence.

The T-Rex, here, like Jaws's shark, is mostly unseen, and capable of 'violent irruptions' like the falling goat leg, or its later deus ex machina attack on the velociraptors at the end of the film. The protagonists' first response to the T-Rex, moreover, allegorises the dangers and incompleteness of vision. The young girl Lex (Ariana Richards) panics, waving a torch's shaft of white light (similar to those in the film's opening scene, and in the scene in Jaws with Gardner's head). She thereby puts herself in danger through the projection-like beams of light, the dinosaur's huge eye dilating menacingly through the car's window. The T-Rex can also be deceived by light. Grant saves the children by waving a flare, so that the 
scene sets up vision as both dangerous and deceptive, and renders this in a reflexive metaphor for cinematic vision.

The scene also encourages a spectatorial drama of knowledge. Just as the unseen suggestion of the approaching dinosaur facilitates the drama of vision, it also functions erotetically. Genarro (Martin Ferrero) tries to explain the vibrations by saying, 'Maybe it's the power trying to come back on', encouraging ambiguity about the potential threat. The alternative to Genarro's hypothesis is also shown and articulated - Lex asks, 'Where's the goat?' Most important, the dramas function closely together here - the answer to Lex's erotetic question is the 'violent irruption' of a fragmented body part landing on the glass roof, frightening and shocking both her and the spectator.

The velociraptors, too, will not remain unseen throughout the film, but their spectacularity can still be marked by 'violent irruptions', such as when one lurches through the cables behind Ellie in the bunker towards the end of the film, just when her guard is down after restoring the electricity. ${ }^{40}$ Even when the full CGI spectacle of the velociraptors is shown, such as in the scene where they stalk the children in the kitchen, Spielberg can still develop reflexive ways to demonstrate the incomplete nature of vision. When Lex hides inside a metal cupboard, desperately trying to close the entrance before a velociraptor reaches her, the camera rapidly dollies forwards towards her, just behind the dinosaur's feet. The cut to the shot of the leaping velociraptor shows it crash into the side of a different cupboard - the image of the child was a reflection. Here Spielberg tricks the spectator as well as the dinosaur, with the incomplete nature of vision rendered in reflexive narrative and cinematic terms. The velociraptors' attacks, however, can also be more erotetically coded in a manner that is facilitated by the technological developments achieved between the making of Jaws and Jurassic Park. When Muldoon tracks them, and thinks he has one in his sights, he is outflanked by another which appears from out of the jungle canopy beside him. This 
could have been filmed as a 'violent irruption', moving swiftly from unseen to the attack. In this instance, however, Spielberg decides to stress the drama of knowledge. This drama begins by establishing that Muldoon has seen one of the velociraptors - they are first shown by unseen movements in the foliage, and then not by a 'violent irruption' but by a slow realisation, as the camera moves slowly over Muldoon quietly extending the handle of his gun. When the trap is finally sprung, the flanking dinosaur pauses long enough for Muldoon to compliment it by saying 'clever girl', so that the audience can note a character's understanding of events rather than a character's shock at events. It is also the case that this scene is the answer to an erotetic question established near the start of the film. When a sceptical brat of a boy (Whit Hertford) tells Grant that a velociraptor sounds like a 'six foot turkey', the palaeontologist frightens the child by explaining the flank attack tactic. Carroll's 'processes of disclosure, discovery, proof, explanation, hypothesis, and confirmation', therefore, cue audiences to expect to see an outflanking attack at some point, and Spielberg does not use a 'violent irruption' to disrupt this erotetic pleasure. ${ }^{41}$

However, this separation of the dramas of knowledge and vision is more the exception that proves the rule than it is evidence that Spielberg only employed a largely unseen menace in Jaws because of technological constraints. Or, in an approximate middle ground between these positions, as Buckland has it, Spielberg 'turned the production limitation into a stylistic feature of his filmmaking'. ${ }^{42}$ Whatever the precise circumstances by which he developed this filmmaking style, Spielberg uses both dramas in these two films, most frequently intertwining them completely, and at points emphasising one drama over the other, with his motivations predominantly determined by dramatic rather than technological considerations. As demonstrated above, even when Spielberg utilised technological advances which allowed him to show the details of dinosaurs in a way that he was never able to show Bruce the shark, he continued to use the same reflexive oscillation between the 
unseen and the seen which I have associated with both the drama of vision and the drama of knowledge. Technological changes allowed Spielberg to extend these dramas, but did not encourage him to dispense with them, so that his intuitions about how spectators respond to these dramas was consistent in both Jaws and Jurassic Park, even if he had additional techniques available to manipulate these spectatorial responses.

Scholarship, then, generally delimits the various ways that film operates. Competing paradigms criticise rival interpretations in epistemological terms - Carroll's cognitivism claims that 'once the reigning psychoanalytic-marxist theory is assessed according to canons of rational enquiry and compared to alternative cognitive theories, it appears baroque and vacuous, indeed, altogether an intellectual disaster', ${ }^{43}$ while Heath's poststructuralism maintains that "to remain at the level of a content analysis $[\ldots]$ is to fail to engage with the fact of film"". ${ }^{44}$ Jaws and Jurassic Park, however, suggest that both of these theories provide appropriate tools to analyse different aspects of film because filmmakers, with Spielberg a clear example, can exploit the very different motivations associated with paradigms that are ostensibly irreconcilable at the purely epistemological level, and can do this in sophisticated reflexive terms.

\section{Notes}

${ }^{1}$ There are, of course, a small number of films that explicitly engage with issues relating to film theory, such as Le Vent D'Est (1969), Riddles of the Sphinx (1977), and News from Home (1977).

2 Stephen Heath, 'Jaws', Ideology and Film Theory', in Movies and Methods Volume II, ed. Bill Nichols (Berkeley: University of California Press, 1985), 509-514. 
${ }^{3}$ Noël Carroll, The Philosophy of Horror, or, Paradoxes of the Heart (London: Routledge, 1990).

${ }^{4}$ For examples of scholarship addressing the epistemological irreconcilability of these paradigms see David Bordwell, 'Contemporary Film Studies and the Vicissitudes of Grand Theory', in Post-Theory: Reconstructing Film Studies, ed. David Bordwell and Noël Carroll (Madison, Wisconsin: University of Wisconsin Press, 1996) 3-36 and Warren Buckland, ‘Critique of Poor Reason', Screen 30 (4): 80-103.

${ }^{5}$ Jacques Lacan, 'Freud's Papers on Technique 1953-1954', The Seminar of Jacques Lacan, Book 1, trans. John Forrester, ed. Jacques-Alain Miller (New York: Norton, 1991).

${ }^{6}$ René Descartes, Principles of Philosophy, trans. Valentine Roger Miller and Reese P. Miller (London: Kluwer, 1982 [1644]).

${ }^{7}$ Carroll, Noël, Mystifying Movies: Fads and Fallacies in Contemporary Film Theory, (New York: Columbia University Press, 1988).

${ }^{8}$ Heath, "'Jaws"”.

${ }^{9}$ Ibid., 513-4, original emphasis.

${ }^{10}$ Ibid., 514.

${ }^{11}$ Carroll, Philosophy, 130.

12 Ibid., 130.

${ }^{13}$ Ibid., 182.

${ }^{14}$ David Bordwell, Narration in the Fiction Film (London: Methuen, 1985), 335.

${ }^{15}$ Carroll does not use the term 'drama of knowledge' to discuss the overall pleasures of erotetic narration, but he does use similar terminology in his discussion of the more specific 'drama of proof'(Philosophy, 102-7, 119, 126-8, 157, 182-90) and 'drama of disclosure' (Philosophy, 144, 182, 186-7). 
${ }^{16}$ Heath, "“Jaws"”, 514.

${ }^{17}$ Ibid., 512.

${ }^{18}$ Ibid., 512.

${ }^{19}$ Ibid., 512-3.

${ }^{20}$ Carroll, Philosophy, 99, original emphasis.

${ }^{21}$ Ibid., 100, original emphasis.

${ }^{22}$ Ibid., 137.

${ }^{23}$ Heath, "“Jaws"”, 514.

${ }^{24}$ Ibid., 513.

${ }^{25}$ Carroll, Philosophy, 182.

${ }^{26}$ Ibid., 100.

${ }^{27}$ Heath, “"Jaws”, 514.

${ }^{28}$ Ibid., 514.

${ }^{29}$ Warren Buckland, Directed by Steven Spielberg: Poetics of the Contemporary Hollywood Blockbuster (New York: Continuum, 2006), 103.

${ }^{30}$ Heath, "Jaws"”, 514.

${ }^{31}$ Buckland, Directed by, 103.

${ }^{32}$ Heath, “Jaws”, 514.

${ }^{33}$ Ibid., 514.

${ }^{34}$ Other than Heath's account of reflexivity in Jaws, most existing scholarship tends to link Spielberg's reflexivity with an auteur-like cinephilia and postmodernism. See Nigel Morris, The Cinema of Steven Spielberg: Empire of Light (London: Wallflower, 2007), 136.

${ }^{35}$ Carroll, Philosophy, 182.

${ }^{36}$ Bruce Isaacs, The Orientation of Future Cinema: Technology, Aesthetics, Spectacle (London: Bloomsbury, 2013), 190. 
${ }^{37}$ Ibid., 190.

${ }^{38}$ Geoff King, Spectacular Narratives: Hollywood in the Age of the Blockbuster (London:

I.B.Tauris, 2000), 74.

${ }^{39}$ Ibid., 48.

40 . This scene also includes another example of a reflexive fragmented limb - Arnold's

(Samuel L. Jackson) arm rests reassuringly on Ellie's shoulder, but when she puts her hand on the arm it swings over her, dismembered at the shoulder.

${ }^{41}$ Carroll, Philosophy, 182.

${ }^{42}$ Buckland, Directed by, 104.

${ }^{43}$ Noël Carroll, 'Cognitivism, Contemporary Film Theory and Method: A Response to Warren Buckland,' Journal of Dramatic Theory and Criticism 6, no.2 (1992): 200. 